\title{
A child death from unsupervised handling of modern technology
}

\author{
WRAS Rajapaksha*, NASP Wijerathna \\ Department of Forensic Medicine, Faculty of Medicine, University of Kelaniya
}

*Corresponding author: Tel: 0714492887. E-mail address: samindarajapaksha@yahoo.com

\begin{abstract}
Parents or guardians should be cautious when allowing the children to handle modern technology. At the same time young children should be supervised thoroughly as their little experiments or mischievous behaviors could lead to fatal injuries. A 6 year old boy was found dead wedged upright between a remote controlled sliding gate and its post at his own house which was tightly pressed against his mid chest. The remote control device was found on the floor beside him. Post mortem examination revealed a compatible patterned abrasion on the back of the chest $40 \mathrm{~cm}$ above the heel which can be explained from the projection of the gate post. There were conjuctival petechiae, and marked congestion of the upper chest and face. Internal examination was negative except for the marked congestion. Cause of death was concluded as traumatic asphyxia. Traumatic asphyxia due to accidental entrapment in a remote controlled sliding gate is rare in forensic literature. This case highlights the importance of close supervision of children and incorporation of properly functioning safety mechanisms in devices with modern technology.
\end{abstract}

Keywords: Traumatic asphyxia, children, electric gate

\section{Introduction}

Parents or guardians should be cautious when allowing the children to handle modern technology. At the same time young children should be supervised thoroughly as their little experiments or mischievous behavior could lead to fatal injuries.

\section{Case report}

A 6 year old active boy was found dead wedged upright between a remote controlled sliding gate and its post at his own house. Police investigations revealed that he was found facing the gate which was tightly pressed against his mid chest while his back was against the gate post. The remote control device was found on the floor beside him. He was unresponsive when found and was pronounced dead on admission to the hospital. Examination of the locus revealed a $10 \mathrm{~cm} \times 7 \mathrm{~cm}$ size vertically placed, metal projection made of 2 parallel blades on the gate post, $90 \mathrm{~cm}$ above the ground. Post mortem examination revealed a compatible patterned abrasion on the back of the chest $90 \mathrm{~cm}$ above the heel which can be explained from the projection of the gate post. (Figure: 1) There were conjuctival petechiae, and marked congestion of the upper chest and face (Figure: 2). Internal examination was negative except for the marked congestion. Cause of death was concluded as traumatic asphyxia. Further investigations by the police revealed that this child has kept the remote controlled key with him. And the caretaker, the grandmother of the child was unaware about child's whereabouts at the moment and assumed that he is watching television in neighbour's house. 


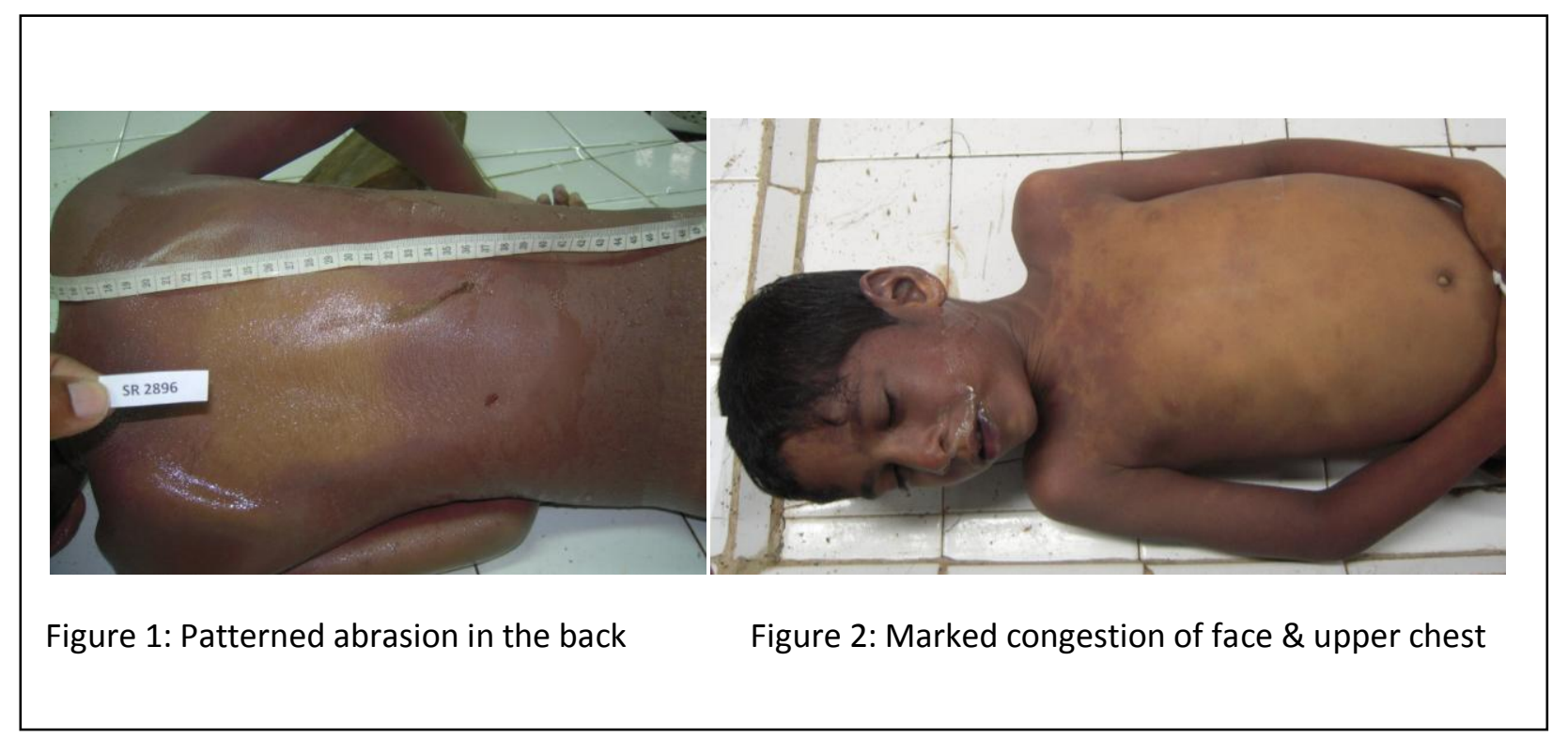

According to further investigations, the sliding gate is heavy and made up of iron bars. It was 15 feet in length and 5 feet in height. Remote controlling $350 \mathrm{~W}$ electric motor supplies the force for sliding movement of the gate. There was a safety mechanism to prevent crushing effect. If there is an unexpected object come into contact, it automatically reverse the gate. But in last 6 inches, the safety mechanism is not effective and it stops with compression of the object without reversing the gate.

\section{Discussion}

Traumatic asphyxia due to accidental entrapment in a remote controlled sliding gate is a rare finding in forensic literature[1][2]. It is further rare to find a case of traumatic asphyxia where the body is held in upright position[3]. Traumatic asphyxia is caused by crushing of chest and abdomen[4][5][6][7][8], but has also been associated with asthma, paroxysmal coughing, protracted vomiting, and jugular venous occlusion. In traumatic asphyxia severe compressive forces are applied directly to chest hindering respiration. A significant increase of venous pressure occurs only when the glottis is closed during chest compression. It is clinically characterized by cervico -facial cyanosis, oedema, subconjunctival hemorrhages, and petechiae on the upper chest and face[4][6][8] ${ }^{8}$. It is due to reflux of blood from the right heart backward through the valveless superior vena cava and the great veins of the head and neck causing engorgement of capillaries. This will leads to Capillary atony, dilatation and stagnation. In this cadaver there was massive congestion and bluish discolouration in upper chest, upper limbs, neck and head regions[4][5][6].

This child had only an imprint abrasion on back of the chest without causing any major injuries to chest wall or internal chest organs and it is due to pliable chest wall of children. In traumatic asphyxia internal injuries are usually minimal[4][5]. Common injuries that are expected with it are rib fractures, pulmonary contusion, pneumothorax and hemothorax. Injury to the heart and great vessels are rare. As in this case, traumatic asphyxia does not cause hydrostatic pulmonary edema because chest compression increases intravascular, interstitial, and alveolar pressures to the same degree; thus, the pressure gradient is unchanged[4]. The lower body is spared with the stigmata of increased venous pressure, possibly because the inferior vena cava is compressed and it prevents reversal of venous flow. Patient morbidity and mortality is usually determined 
by the presence and severity of associated cardiovascular, pulmonary, and neurological injuries.

Investigation into the safety mechanism of the gate explained why this child was entrapped and held between the gate and the gate post causing persistent pressure over the chest wall and death due to traumatic asphyxia. The unsupervised handling of the modern technology and the delay due to unawareness has of the safety mechanisms had contributed to the death of this child. Therefore it is mandatory to observe and supervise our children closely especially when they are handling modern technology.

\section{Conclusions and recommendations}

Traumatic asphyxia due to accidental entrapment in a remote controlled sliding gate is rare finding in forensic literature. Immature, inquisitive children can be victims of such tragedies especially when they are unsupervised. We propose that the children should be closely supervised especially when they are handling modern technology. Furthermore, a safety mechanism should be developed in these gates which will cease to function only when the two points (gate and gate post) are in contact.

\section{References}

1. Sklar DP, Baack B, McFeeley P, Osler T, Marder E, Demarest G.. Traumatic asphyxia in New Mexico: a five-year experience. Am J Emerg Med. 1988;6:219-23,
2. RW Byard, KA Hanson, RA James, Fatal unintentional traumatic asphyxia in childhood, Journal of Paediatrics and Child Health, Volume 39, Issue 1, pages 31-32, January 2003

3. Bülent Eren, Nursel Türkmen, Recep Fedakar, An unusual case of thorax compression, J Ayub Med Coll Abbottabad 2008;20(1), 134-135.ref].

4. Ibarra P, Capan L.M, Wahlander S, Sutin K.M, Difficult Airway Management in a Patient with Traumatic Asphyxia; Anesth Analg 1997;85:216-8

5. Miyaishi S, Yoshitome K, Yamamoto Y, et al; Negligent homicide by traumatic asphyxia; Int J Legal Med Jan 142004

6. Koniaris L.G, Kross M.E, O'malley N, Cornwell E.E, Traumatic asphyxia by unwitnessed cardiac arrest; Sothern medical jurnal,sep 2000;93:905-908

7. Young Joo Choi, Sung Ju Lee, Hyung Jin Kim, Jin Ho YimKorean; Bilateral Retrobulbar Hemorrhage and Visual Loss Following Traumatic Asphyxia J Ophthalmol. 2010 December; 24(6): 380-383

8. Moore D, Mayer J.H, Otto Gago, Traumatic Asphyxia; Chest;1972;62;634-636

\section{Contribution of authors}

Performing the autopsy-WRASR

Opinion- WRASR, NASPW

Writing the manuscript - WRASR

Revising the manuscript- WRASR, NASPW 